\title{
CONVENTIONAL RENAL CELL CARCINOMA WITH GRANULOMATOUS REACTION
}

Srinivas Gubbala1, Satyanarayana ${ }^{2}$

\section{HOW TO CITE THIS ARTICLE:}

Srinivas Gubbala, Satyanarayana. "Conventional Renal Cell Carcinoma with Granulomatous Reaction". Journal of Evolution of Medical and Dental Sciences 2014; Vol. 3, Issue 48, September 29; Page: 11626-11630,

DOI: $10.14260 /$ jemds/2014/3526

ABSTRACT: Granulomatous inflammation is a distinctive pattern of chronic inflammatory reaction characterized by microscopic aggregation of activated macrophages which often develop epithelioid appearance and multinucleate giant cells. Granulomas are encountered in limited number of infectious and some non-infectious conditions. Granulomas have been described within the stroma of malignancies like carcinomas of the breast and colon, seminoma and Hodgkin's lymphoma, where they represent T-cell-mediated reaction of the tumor stroma to antigens expressed by the tumor. Granulomatous reaction in association with renal cell carcinoma (RCC) is uncommon, with only few published reports in the literature. We describe a case of conventional (clear cell) RCC associated with epithelioid cell granulomas within the tumor parenchyma.

KEYWORDS: Granulomatous inflammation, renal cell carcinoma.

INTRODUCTION: Granulomatous inflammation is a distinctive pattern of chronic inflammatory reaction characterized by focal accumulation of activated macrophages that often develop an epithelioid appearance. Granulomas are encountered in a limited number of immunologically mediated infectious and some non-infectious conditions. ${ }^{1}$

Granulomas may also occur within malignancies like carcinomas of the breast, kidney, colon and Hodgkin's lymphoma ${ }^{2-4}$ Granulomatous reaction in association with renal cell carcinoma (RCC) is uncommon, with only few published reports in the literature. We describe a case of conventional (clear cell) RCC associated with epithelioid cell granulomas within the tumor parenchyma.

In regions with a high incidence of tuberculosis, it is difficult to differentiate tumor-related granulomatous reactions from that due to concomitant tuberculosis. This difficulty could have implications on the modalities of treatment that can be offered to the patient.

CASE REPORT: A 56 year old female patient was admitted in the hospital with complaints of gross painless hematuria of 2 months duration and pain in left iliac region radiating to back since 6 months duration. Patient is known case of hypertension, Type 2 diabetes mellitus and CAD. On admission her vitals were normal and all the hematological and biochemical parameters were within normal limits.

Serology for Human immunodeficiency virus (HIV), Hepatitis B surface antigen (HBsAg) and antibody for Hepatitis $\mathrm{C}$ virus (HCV Ab) were negative. There is no past or present history suggestive of tuberculosis or any history of contact with tuberculosis. Chest X-Ray was normal in the patient. CT abdomen revealed a $3 \times 2 \mathrm{~cm}$ heterogeneously enhancing mass in the upper pole cortex of left kidney with a large exophytic component and no evidence of intra-abdominal lymphadenopathy. The patient underwent Laparoscopic Left radical nephrectomy.

PATHOLOGY: On gross examination, Left Nephrectomy specimen revealed 3.5 x $3 \mathrm{~cm}$ well circumscribed mass in the upper pole of the kidney. The capsule over the mass was stretched but 
there was no breach of capsule, The hilar vessels and ureter are unremarkable. The cut section of the tumor mass revealed grey yellow to tan variegated appearance with foci of hemorrhage.

The microscopic section from the tumor revealed sheets and alveolar clusters of tumor cells supported by delicate network of small blood vessels. The tumor cells had clear cytoplasm with nuclear features corresponding to Fuhrman's nuclear grade I. The histo-pathological diagnosis offered was conventional/clear renal cell carcinoma with granulomatous reaction.

The most conspicuous feature noted was the presence of multiple non-caseating granulomas with Langhans and foreign body type multinucleated giant cells within the viable tumor parenchyma and fibrous septae intercepting the tumor. Granulomas were not present in the adjacent native normal renal parenchyma. Special stains for acid fast bacilli (Ziehl-Neelson) and fungi (Gomori's methanamine silver and periodic acid Schiff with diastase) did not reveal any micro-organisms. There were no schaumann and asteroid bodies or calcium oxalate crystals. Mycobacterial cultures and polymerase chain reaction (PCR) for Mycobacterium tuberculosis could not perform.

The granulomas were confined to the tumor and in view of the absence of granulomas in the non-tumorous renal parenchyma, lack of clinical features suggestive of tuberculosis and normal chest $\mathrm{X}$-ray, these granulomas were considered to be tumor related and the patient was not treated with anti-tuberculous drugs.

DISCUSSION: There are few published reports of association of RCC with granulomatous reaction in the literature.4-8 The types of RCC associated with granulomas are variable. In the present report the tumor was of the conventional (clear cell) type, which is similar to that described in other reports. ${ }^{5-7}$ The RCC had sarcomatoid features in the report by Piscioli et al, ${ }^{4}$ and was of papillary type in the case described by Marinides et al. ${ }^{8}$

Fuhrman's nuclear grade was I in our case similar to all tumors that were also grade I in the report by Hes et al. ${ }^{5}$ All the granulomas were of the epithelioid cell type. The location of granulomas is variable, with granulomas being described within the tumor parenchyma, tumoral stroma as well as at the periphery of the tumor. ${ }^{4-7}$

In our study, the granulomas were present within the tumoral parenchyma as well as in the fibrous septa intercepting the tumor. The other reports describe granulomas confined to the tumor, except the study by Hes et al, where one case showed granulomas within the normal kidney in the vicinity of the tumor.4-7

In the previously published reports, the granulomas were non-necrotizing. There granulomas have been described as "Sarcoid-like reaction"/"Sarcoid-like granulomas."4,6,7 Hes et al, describe RCC with non-caseating granulomas. ${ }^{5}$ There is also a case report of renal sarcoidosis coexisting with hypernephroma. ${ }^{9}$

In our study the granulomas were also non-necrotizing and no acid fast bacilli or fungal micro-organisms were detected on performing the special stains. In view of lack of clinical factures to suggest tuberculosis as well as normal chest radiographs, our patient was not treated with antituberculous therapy. However, it was not possible to completely exclude tuberculosis as mycobacterial culture and PCR were not performed.

MTB-PCR detects the presence or absence of mycobacterium DNA, without a clue as to whether the disease is active or dormant (only showing a healed focus). ${ }^{10}$ 
Hence, clinical correlation is required and it is not sufficient if the MTB-PCR is positive. In a country like India, with a high prevalence of tuberculosis, a positive PCR may not necessarily indicate an active action.

Tumor-associated granulomas represent an immune response of the tumor stroma to antigens expressed by the tumor, and manifests as a local T-cell-mediated reaction.5-7,10 The possibilities to be considered in any tumor associated with granulomatous reaction are: (a) the granulomas are a reaction to tumor-related antigens and (b) there is co-existence of chronic granulomatous process like tuberculosis/sarcoidosis and tumor.

CONCLUSION: We report a case of RCC associated with non-necrotizing granulomas. Based on the morphological features of granulomas, it is not possible to entirely exclude concomitant tuberculosis, especially in a country like India with a high incidence of tuberculosis. However, the lack of granulomas in the adjoining renal parenchyma along with the absence of supportive clinical and radiological features tipped the balance in favor of tumor-related granulomatous reaction. Nevertheless, this is a difficult, but important distinction to be made that has major therapeutic implications.

LEARNING POINTS: RCC associated with non-necrotizing granulomas is a rare occurrence but in areas with a high incidence of tuberculosis like India histopathological interpretation along with clinical and radiological evaluation is required to establish the etiology.

\section{REFERENCES:}

1. Kumar V, Abbas AK, Fausto N. Acute and Chronic inflammation. In: Pathologic Basis of Disease. Saunders, seventh edition, 2006; 47-86.

2. Coyne JD. Colonic carcinoma with granulomatous (sarcoid) reaction. J Clin Pathol 2002; 55: 708-9.

3. Santini D, Pasquinelli G, Alberghini M, Martinelli GN. Taffurelli M. Invasive breast carcinoma with granulomatous response and deposition of unusual amyloid. J Clin pathol 1992; 45: 885-8.

4. Piscioli I, Donato S, Morelli L, Del Nonno F, Licci S. Renal cell carcinoma with sarcomatoid features and peritumoral sarcoid-like granulomatous reaction: Report of a case and review of the literature. Int J Surg Pathol 2008; 16 (3): 345-8.

5. Hes $\mathrm{O}$, Hora $\mathrm{M}$, Vanecek $\mathrm{T}$, et al. Conventional renal cell carcinoma with granulomatous reaction: a report of three cases. Virchows Arch 2003; 443: 220-1.

6. Campbell F, Douglas-Jones AG. Sarcoid-like granulomas in primary renal cell carcinoma. Sarcoidosis 1993; 10: 128-31.

7. Kovacs J, Varga A, Bessenyei M, Gomba S. Renal cell cancer associated with sarcoid-like reaction. Pathol Oncol Res 2004; 10: 169-71.

8. Marinides GN, Hajdu I, Gans RO. A unique association of renal cell carcinoma with sarcoid reaction in the kidney. Nephron 1994; 67: 477-80.

9. Bottone AC, Labarbera M. Asadourian A, Barman A, Richie C. Renal sarcoidosis coexisting with hypernephroma. Urology 1993; 41: 157-9. 


\section{CASE REPORT}

10. Khurram M, Tariq M, Shahid P. Breast cancer with associated granulomatous axillary lymphadentitis: A diagnostic and clinical dilemma in regions with high prevalence of tuberculosis. Pathol Res Pract 2007; 203: 699-704.

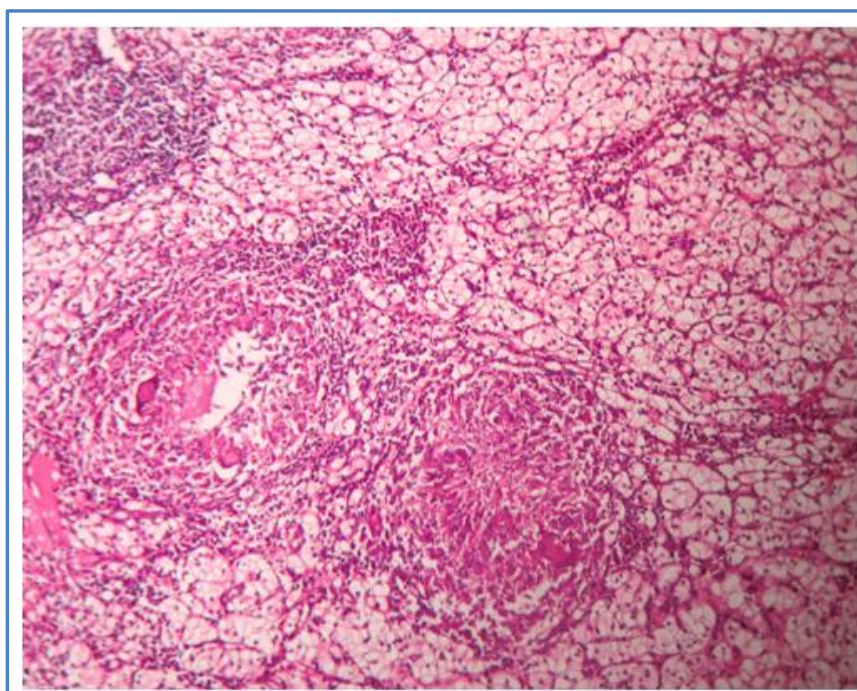

Figure no:1

Scattered epithelioid cell granulomas with multinucleate giant cells within the parenchyma of clear cell carcinoma .

(Hematoxylin \& Eosin stained sections, X 100 )

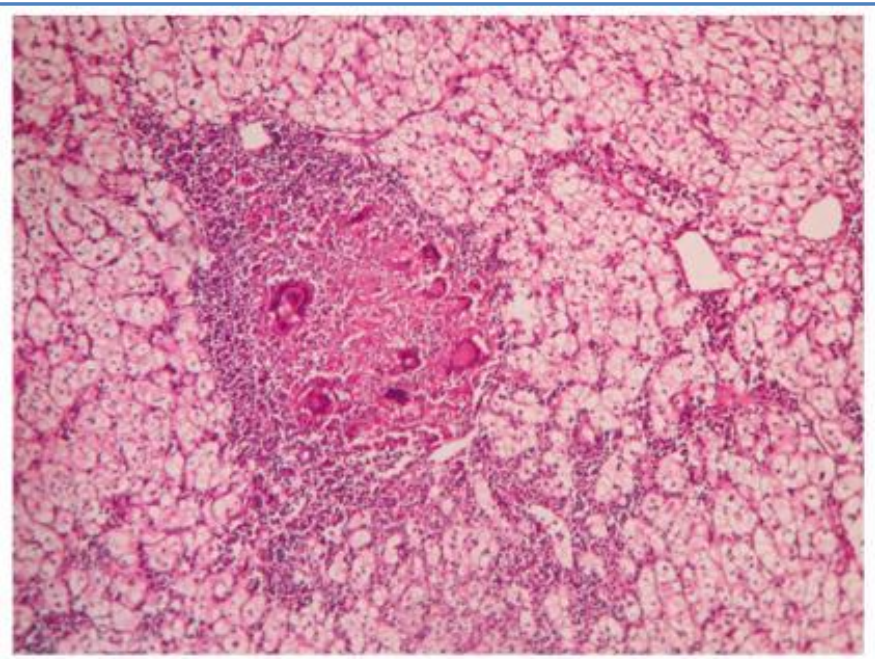

\section{Figure no :2}

Non -necrotizing granuloma with epithelioid histiocytes, and Langhans multinucleate giant cells within parenchyma of renal cell carcinoma .

(Haematoxylin \& Eosin stained section, X 100) 


\section{CASE REPORT}

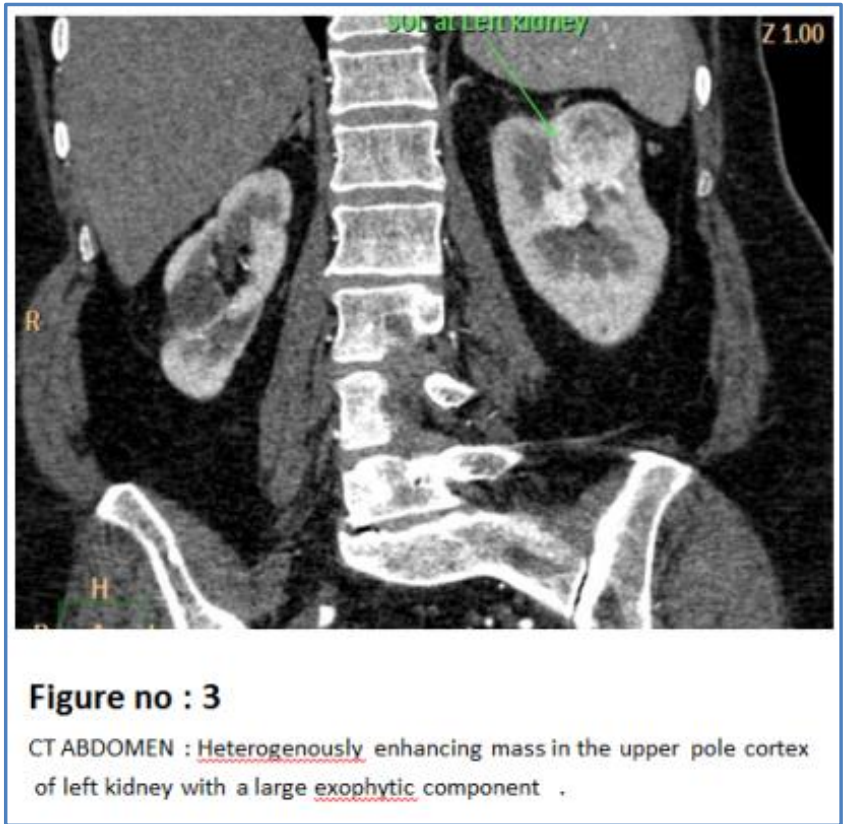

\section{AUTHORS:}

1. Srinivas Gubbala

2. Satyanarayana

\section{PARTICULARS OF CONTRIBUTORS:}

1. Assistant Professor, Department of Pathology, Kamineni Institute of Medical Sciences, Narketpally, Telangana.

2. Professor and HOD, Department of Pathology, Kamineni Institute of Medical Sciences, Narketpally, Telangana.

\section{NAME ADDRESS EMAIL ID OF THE} CORRESPONDING AUTHOR:

Dr. Srinivas Gubbala,

Department of Pathology,

Kamineni Institute of Medical Sciences,

Narketpally, Telangana.

Email: srinivas.path@gmail.com

Date of Submission: 11/09/2014.

Date of Peer Review: 12/09/2014.

Date of Acceptance: 19/09/2014.

Date of Publishing: 29/09/2014. 